\title{
A Utilização do Facebook no Contexto Acadêmico: o Perfil de Utilização e as Contribuições Pedagógicas e para Educação em Saúde
}

\author{
Prof $^{\mathrm{a}} \mathrm{Dr}^{\mathrm{a}}$ Gabriela Eyng Possolli — Faculdades Pequeno Príncipe — gabriela.possolli@ fpp.edu.br \\ Gabriel Lincoln do Nascimento-Faculdades Pequeno Príncipe \\ Prof ${ }^{a}$ Esp. Juliana Ollé Mendes da Silva— Faculdades Pequeno Príncipe
}

\section{Resumo}

O objetivo deste estudo é refletir sobre o uso do Facebook por discentes e docentes e seus potenciais didático-pedagógicos. Sua utilização em relacionamentos sociais é significativa e seus potenciais educacionais são progressivamente descobertos. Produções científicas acerca da relevância desta rede social são recentes, caracterizando um campo que necessita aprofundamento. Esta é uma pesquisa descritiva, qualitativa, que analisou dados obtidos a partir de um instrumento com questões objetivas e discursivas em que houve a participação de alunos e professores de cursos de graduação na área da saúde de uma IES filantrópica de Curitiba. A amostra compreendeu 35\% dos docentes e 55\% dos discentes. Dentre os resultados destacam-se que $75 \%$ dos participantes utilizam o Facebook mais de 5 dias na semana e usam seu mensageiro para comunicação, em grupo ou individualmente. $39 \%$ dos participantes utilizam o Facebook de maneira ativa, como autores de postagens de elaboração própria, enquanto $61 \%$ são mais passivos, curtindo, comentando ou compartilhando postagens de outrem. Nas considerações finais foram abordados processos da cultura participativa, englobando contribuições do Facebook para: afiliação, expressões, circulação e solução colaborativa; e o uso para formação e atuação profissional na saúde.

Palavras-Chave: Facebook; instituições de educação superior (IES); tecnologias educacionais na área da saúde; comunidade virtual de aprendizagem.

\section{The Use of Facebook on Academic Contexts: User Profile and Its Pedagogic and Health Education Contributions}

\begin{abstract}
This study aims to reflect upon professors and students' use of Facebook and its didacticpedagogical potentials. It has significant utilisation for social relationships furthermore, its educational potentials have been progressively found. Scientific works about the relevance of this social network are recent, making this a field that still needs further exploration. This research is descriptive and has a qualitative take that analysed answers on an instrument containing objective and discursive questions. The participation included professors and students of health graduation courses from a non-profit institution of Curitiba, Brazil. The sample include, respectively, $35 \%$ and $55 \%$ of the institutions' professors and students. Among the results it stands out that $75 \%$ of the participants used Facebook more than 5 days a week and use it for communication, both within groups and individually. 39\% of the participants uses Facebook actively, authoring the content they share, whereas $61 \%$ are more passive users, liking, commenting and sharing other's content. Under final considerations four processes of participative culture were covered, encompassing Facebook's contribution on affiliation, expression, circulation and on collaborative solution and its use on formation and acting of health professionals.
\end{abstract}

Keywords: Facebook; higher education; educational technologies for health education; Virtual Learning Community.

\section{INTRODUÇÃO}

O presente artigo versa sobre o Facebook, a rede social mais popular entre docentes e discentes na contemporaneidade, buscando aferir seus potenciais didático-pedagógicos na área da saúde. Partindo do objetivo: compreender a utilização da rede social Facebook por acadêmicos e professores da área da saúde, foi possível estabelecer seus potenciais didático- 
pedagógicos e apontar estratégias de ação. Na construção do projeto de pesquisa partiu-se da hipótese de que a rede social Facebook, possui grande penetração na educação superior. Esta rede social apresentou crescimento expressivo nos últimos quatro anos, até o momento sem indícios de declínio, tendo um horizonte promissor de incremento de funcionalidades.

A utilização da rede social Facebook entre jovens do ensino médio e em idade universitária é significativa em seus relacionamentos sociais e grupos de afinidade e seus potenciais didático-pedagógicos vêm sendo descobertos pelos docentes. Uma revisão sistemática publicada em 2015 contemplando publicações de 2011 a 2014 encontrou 270 artigos em periódicos e anais de eventos sobre o Facebook no campo das ciências sociais e humanas no idioma português (OMENA, JORGE, 2015). Indicando um baixo número de publicações a esse respeito tendo em vista a relevância do Facebook na vida dos jovens, pesquisas ainda recentes, residindo aqui um dos pontos que justifica esse estudo. $\mathrm{O}$ grupo de pesquisa que realizou esse estudo está vinculado ao programa de pós-graduação em Ensino nas Ciências da Saúde, com projeto de pesquisa protocolado no Comitê de Ética em Pesquisa da instituição da Faculdades Pequeno Príncipe, aprovado na plataforma Brasil sob o número de protocolo 816.950. A coleta de dados para a pesquisa foi feita a partir de um questionário online em que foram convidados professores e alunos de cursos superiores da área da saúde de uma IES de Curitiba. A participação foi registrada a partir de um instrumento quanti-qualitativa, que incluía questões objetivas e dissertativas. Os dados resultantes foram categorizados e interpretados.

\section{FUNDAMENTAÇÃO TEÓRICA}

Tecnologias de informação e comunicação (TICs) causaram uma revolução na educação, alterando a rotina de professores e alunos. Especialmente nas duas últimas décadas, com a popularização da internet e mais recentemente com a intensa proliferação de redes sociais, os ambientes online têm ganhado força como ferramentas didáticas relevantes para acesso a informação, interação e produção coletiva de saberes. No ciberespaço uma inédita conjuntura de fatores desacomoda estruturas e pressupostos tradicionais trazendo à tona novas problematizações por meio de novos recursos didáticos (CASTELLS, 1999; LEVY, 1999).

O movimento possibilitado pelas tecnologias digitais que constituem o ciberespaço dinamizou as formas de compartilhar conhecimento, criando novos modelos de trocas sociais (weblogs, e-mail, chats, fotologs, redes sociais, entre outros). Essas trocas ultrapassam limites de espaço e tempo, permitindo a criação de novas formas de cultura: a cibercultura. As gerações X e Y, fortemente adaptadas a cibercultura, tomam espaço nas universidades e no mercado de trabalho, revolucionando a vida cotidiana. Jovens na faixa etária dos 15 aos 35 anos, tem a tendência de "realizar várias atividades ao mesmo tempo. Navegam em redes sociais, enquanto estudam, assistem televisão e escutam música". Tudo ao mesmo tempo. Mas não são só os jovens que agem assim. Apesar de esta ser uma "característica das gerações $\mathrm{x}$ e y, muitos adultos, e até mesmo pessoas da terceira idade, já incorporaram estas características" (DORNELLES, 2012).

Com os dispositivos móveis, as formas de agir, pensar e se relacionar dessas gerações ganham novos contornos. A era da mobilidade parece ser um caminho sem volta por trazer praticidade, flexibilidade e agilidade ao cotidiano. Dados da Pagtel; E.Life (2014), uma empresa de pagamentos online, demonstram que os aplicativos para redes sociais e para enviar mensagens foram usados por $96 \%$ dos usuários brasileiros de tablets e smartphones, sem uma variação significativa entre faixas etárias ou níveis socioeconômicos diferentes. A mesma tendência se percebe nos aplicativos destinados a transações bancárias, jogos, músicas e vídeos (LEITE, 2013). Esses dados corroboram com as análises de vários autores, tais como Beline et al. (2007), Litwin (2009), Santos e Vechia (2007), ao afirmarem as possibilidades de democratização da informação e rompimento de barreiras socioeconômicas no contexto do ciberespaço. 
Na educação superior, o incremento da cibercultura reconfigura a comunicação e o relacionamento entre a sociedade e a comunidade acadêmica, bem como instaura perspectivas inovadoras para o processo de ensino-aprendizagem. Em meio às diversas possibilidades de uso das TICs no universo educacional, as redes sociais têm se destacado como ferramentas de comunicação e mediação pedagógica, com grande ênfase ao uso do Facebook por se tratar da rede social mais utilizada no mundo. Atualmente esta rede conta com mais de 1 bilhão de usuários ativos mensais (FACEBOOK, 2015).

Um levantamento feito pela empresa de cibersegurança AVG (2013) relata que o Brasil possui $55 \%$ da população conectada à internet (dados referendado pelo IBGE em 2012). O uso da internet por crianças e adolescentes cujos pais usam a rede é de $97 \%$, já com relação à presença dos filhos de pais usuários de internet no Facebook: a taxa brasileira é de $54 \%$, mais que o triplo da média dos demais países $(16 \%)$ e nove vezes superior à da Austrália (FOLHA DE S. PAULO, 2014). Esses dados mostram que as novas gerações brasileiras possuem um alto índice de inclusão digital. Essas crianças e adolescentes futuramente serão alunos da educação superior e as IES precisam agregar essa ferramenta como estratégia de comunicação e ensino-aprendizagem. F/Nazca Saatchi \& Saatchi indica que "43 milhões de usuários acessam a internet através de dispositivos móveis no Brasil", já um levantamento feito em 2013 indicou que para os brasileiros o WhatsApp é o aplicativo favorito, seguido do WeChat e o Facebook Messenger. (MOMENTO, 2014).

O Brasil é o $2^{\circ}$ país em número de usuários do Facebook, atrás somente do EUA. No final de 2011, o Brasil tinha 35,1 milhões de usuários, um ano depois, o número chegou perto de dobrar (64,8 milhões). Desse modo, a penetração do Facebook no Brasil se aproxima de 32,4\% da população de 201 milhões. Ao avaliar apenas a população com acesso a internet o Facebook abrange $82,32 \%$. Para a educação superior é importante notar que um terço dos usuários do Facebook está em idade universitária (18 a 24 anos). Os jovens inserem a internet em todas as áreas de sua vida, e costumam utilizar a rede inclusive para buscar conteúdos educacionais e grupos de interesse para complementar os estudos. Com o tempo, o Facebook tem disponibilizado cada vez mais possibilidades para que IES e professores melhorarem a comunicação e diversifiquem as estratégias de ensino. (O ESTADO DE S. PAULO, 2013).

\section{METODOLOGIA}

Esta é uma pesquisa descritiva de cunho qualitativo, na qual se analisam dados obtidos a partir de um instrumento com questões objetivas e discursivas. Os participantes foram alunos e professores de cursos de graduação na área da saúde de uma IES filantrópica de médio porte localizada em Curitiba-PR. Para habilitar a participação os sujeitos precisavam ser maiores de 18 anos e concordar em participar espontaneamente. Os questionários foram disponibilizados por meio da ferramenta de formulários na plataforma Google Docs. Uma página explicativa com um convite foi enviada com o link de participação.

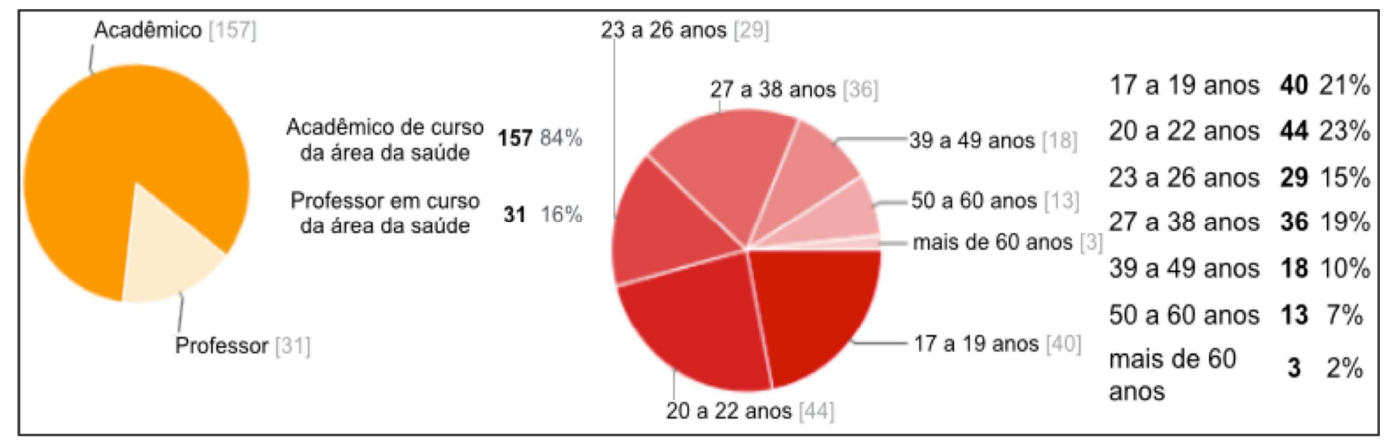

Figura 1 - Amostra da Pesquisa

Fonte: Elaboração própria com base na pesquisa de campo 
O projeto que originou este artigo foi aprovado pelo Comitê de Ética em Pesquisa, que avaliou os aspectos éticos e sua viabilidade, visando garantir proteção e precaução frente ao objeto de estudo (seres humanos). O preenchimento das questões era liberado apenas após a aceitação do termo de consentimento (5 pessoas não aceitaram ). $\mathrm{O}$ gráfico da figura 1 demonstra o total de participantes em cada grupo e as faixas etária. A amostra de pesquisa inclui 183 participações, sendo 31 de docentes e 157 de acadêmicos (compreendendo, respectivamente $35 \%$ e $55 \%$ do universo de pesquisa).

\section{APRESENTAÇÃO E DISCUSSÃO DOS RESULTADOS}

\subsection{Utilização de Redes Sociais e Frequência de Acesso ao Facebook}

Depois da definição do tipo de participante (professor ou acadêmico) e da faixa etária buscou-se verificar a utilização das redes sociais mais significativas no Brasil. Foi solicitado que cada participante classificasse em forma de ranking as redes sociais mais usadas. Para que o resultado fosse mais condizente com a realidade foi permitido classificar duas redes sociais em primeiro lugar ou duas em segundo (por exemplo) caso utilizassem com a mesma frequência. Foi permitido marcar "nunca" caso alguma rede social não fosse utilizada. Segundo a prática dos participantes as redes sociais mais utilizadas são o Facebook e o WhatsApp, o que referenda pesquisas atuais que dizem:

O jovem internauta brasileiro possui, em média, perfil em não uma, mas SEIS
redes sociais. As mais populares são: Facebook ( $96 \%$ dos entrevistados possuem
perfil), YouTube (79\%), Skype (69\%), Google+ $(67 \%)$ e Twitter (64\%). Mas eles
não estão só presentes, com perfis que às vezes se tornam inativos. Os internautas
interagem cada vez mais e navegar por estas redes é um hábito de $90 \%$ de jovens
de todo o país com idade entre 15 e 32 anos. Boa parte do acesso às redes ocorre
em dispositivos móveis. (MORAIS, 2014)

É importante ressaltar as diferenças entre essas redes sociais no que se refere às suas ferramentas comunicativas e potenciais para uso pedagógico. O WhatsApp (aplicativo móvel para troca de mensagens instantâneas e compartilhamento de vídeos e fotos via celular), Instagram (compartilhamento de fotos) e o Twitter (microblog que permite compartilhamento de pequenos textos e links) não podem ser considerados redes sociais com capacidade para se tornarem AVAs, uma vez que um software educacional para ser denominado como AVA deve apresentar as seguintes funcionalidades:

Controle de Acesso (definição de usuário, senha e perfil de acesso); Organização do Ambiente com menus e ferramentas agrupadas por categorias; Controle de tempo para as atividades; Comunicação síncrona e assíncrona; Espaço privativo conforme o tipo de acesso de cada usuário; Materiais didáticos e recursos multimídia atualizados e adequados; Apoio online (tutoria); Avaliação e auto-avaliação. (POSSOLLI, 2012, p.79).

A partir desse entendimento somente as redes sociais Google+, LinkedIn e Facebook podem ser utilizadas como ambientes virtuais de aprendizagem considerando a presença de ferramentas de postagem de conteúdos e interação que possibilitam comunicação síncrona e assíncrona e o registro de conteúdos pelos usuários. Considerando o fato de que o LinkedIn é estruturado para contatos profissionais e o Google+ é mais usado para compartilhamento de documentos e comunicador instantâneo. Assim pode-se concluir que dentre estas redes sociais a única que apresenta potencial para contribuir pedagogicamente como AVA na educação superior é o Facebook, tanto por suas funcionalidades, quanto pelo número expressivo de usuários habituais. Nos gráficos contidos na figura 2 estão os resultados para cada rede social: 


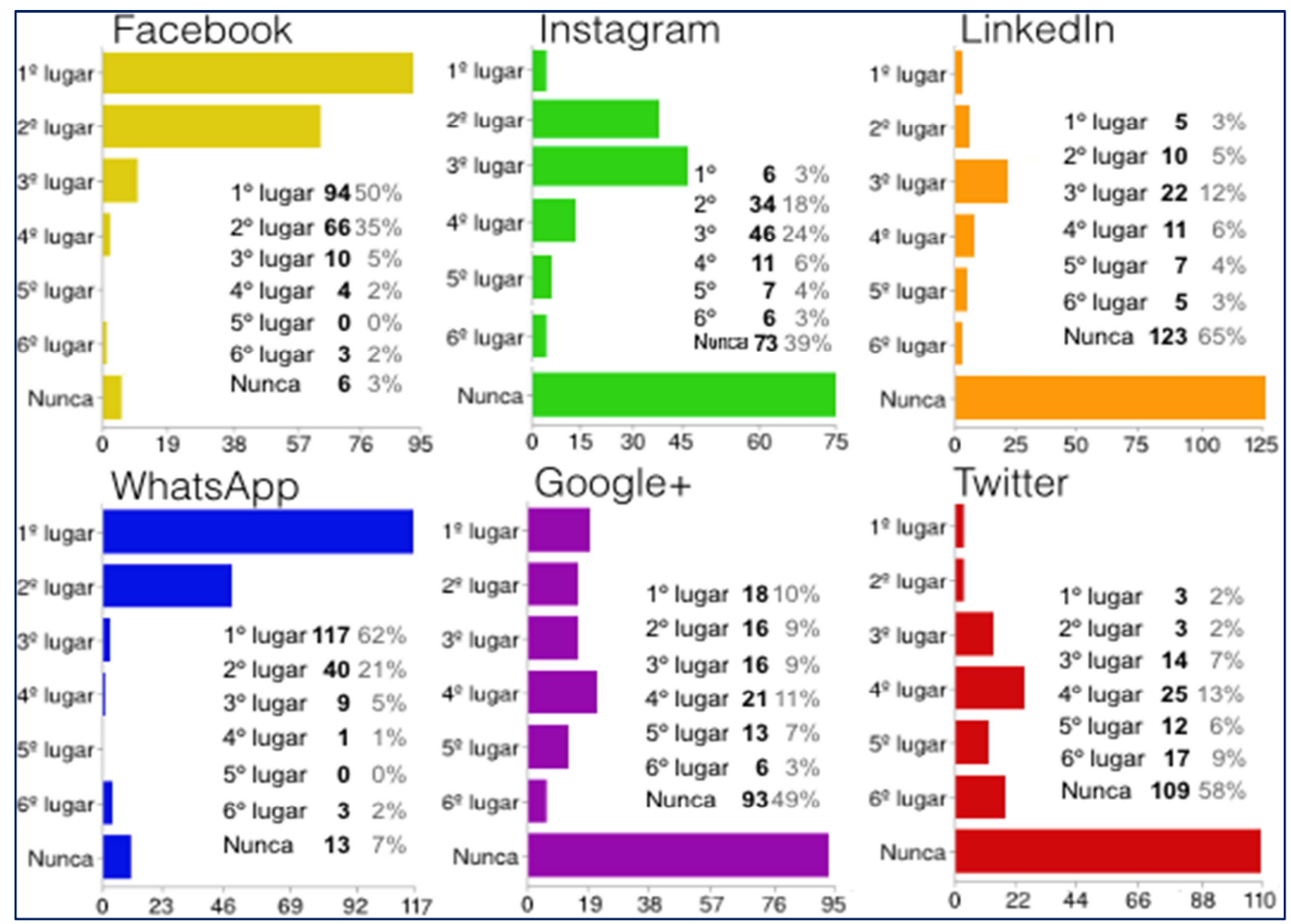

Figura 2 - Gráficos indicadores de ranking de utilização das principais redes sociais Fonte: Elaboração própria com base na pesquisa de campo

$\mathrm{Na}$ terceira questão foi solicitado escolher dentre valores de uma escala, a frequência de utilização do Facebook (gráfico da figura 3), em que perguntou-se: "Tendo acesso livre à internet, qual sua frequência de utilização do Facebook considerando sua rotina semanal normal?". O resultado foi surpreendente. $75 \%$ admitiu utilizar mais de 5 dias na semana, ou seja, faz parte da rotina diária.

\begin{tabular}{|c|c|c|c|}
\hline $7 e s$ mer sem & Mais de 5 dias por semana & 141 & $75 \%$ \\
\hline 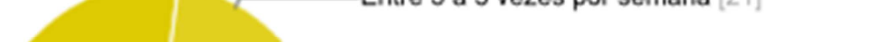 & Entre 3 a 5 vezes por semana & 21 & $11 \%$ \\
\hline de 1 ou 2 dias por ser & Cerca de 1 ou 2 dias por semana & 9 & $5 \%$ \\
\hline dias em um mês $[0]$ & Entre 2 a 3 dias em uma quinzena & 2 & $1 \%$ \\
\hline [- Tenho cadastro no Facebook...[1] & Entre 2 a 3 dias em um mẻs & 0 & $0 \%$ \\
\hline L Nunca tive cadastro no Facebook [1] & $\begin{array}{l}\text { Tenho cadastro no Facebook mas } \\
\text { entro muito pouco }\end{array}$ & 1 & $1 \%$ \\
\hline & $\begin{array}{l}\text { Não tenho cadastro no Facebook } \\
\text { (ja tive) }\end{array}$ & 8 & $4 \%$ \\
\hline Mais de 5 vezes por semana [141] & Nunca tive cadastro no Facebook & 1 & $1 \%$ \\
\hline
\end{tabular}

Figura 3 - Gráficos a respeito da frequência de utilização da rede social Facebook. Fonte: Elaboração própria com base na pesquisa de campo.

\subsection{Perfil de Uso, Ferramentas de Comunicação e de Conteúdo no Facebook}

A quarta questão diz respeito ao perfil de utilização, se é mais ativa (39\%) ou mais passiva (61\%). A opção referente a utilização mais ativa era a seguinte: "Costumo postar frases sobre assuntos que gosto ou situações cotidianas. As vezes posto fotos pessoais e compartilho mensagens de páginas que navego. Também leio as atualizações dos meus contatos curtindo e comentando o que me chama atenção". A utilização mais passiva estava retratada na alternativa: "Leio as atualizações dos meus contatos curtindo o que eles postam, e as vezes, comentando alguma postagem. As postagens no meu perfil são menos frequentes e no geral dizem respeito a assuntos que considero 
interessantes que compartilho de pessoas ou páginas do Facebook". Verifica-se assim o que é possível observar navegando pelo Facebook: a maior parte das pessoas não atua como autor, mas como reprodutor de postagens de outros. Rodeghiero (2014) referenda essa análise ao expor que o processo de aprendizagem nas mídias sociais ocorre de uma maneira em que "os alunos fazem papel de professores de si mesmos e de seus pares", gerando conteúdo online ou selecionando materiais e pontos de vistas, atuando principalmente de duas formas: "postam e compartilham em um processo de criação e/ou comentam e curtem consumindo essas informações".

As questões cinco e seis buscaram verificar como os participantes usam o Facebook no que diz respeito aos dois enfoques principais de ambientes virtuais de aprendizagem: comunicação e postagens de conteúdos. A questão cinco perguntava: "Como ferramenta de comunicação quais recursos do Facebook você utiliza?". Os resultados são expostos na tabela 1:

\begin{tabular}{|l|c|}
\hline \multicolumn{1}{|c|}{ Ferramenta de comunicação } & Ocorrências \\
\hline Mensagens (inbox): enviadas para verificação posterior, como um correio eletrônico & 120 \\
\hline Mensagens (chat): chamando um contato online e originando conversa em tempo real & 104 \\
\hline Inclusão de mensagens na linha do tempo de meus contatos & 63 \\
\hline Postagem de mensagens em grupos que participo (nova mensagem ou comentário) & 92 \\
\hline Participação em eventos (criando eventos ou postando comentários) & 50 \\
\hline
\end{tabular}

Tabela 1 - Quais ferramentas de comunicação são utilizadas

Fonte: Elaboração própria com base na pesquisa de campo.

Para comunicar-se a principal ferramenta é o mensageiro do Facebook, tanto para mensagens online quanto para leitura posterior, em grupo ou individualmente. A postagem em grupos também é relevante, enquanto a inclusão de mensagens diretamente na linha do tempo de um contato ou participação em eventos é menos utilizada. Desse modo verifica-se que é interessante a criação de grupos para turmas ou disciplinas facilitadores da comunicação entre um conjunto de pessoas.

A questão seis perguntava: "Que tipo de conteúdo, de autoria própria, você posta em sua linha do tempo?". As respostas foram organizadas na tabela 2.

\begin{tabular}{|l|c|}
\hline \multicolumn{1}{|c|}{ Tipo de conteúdo } & Ocorrências \\
\hline Fotos: pessoas, grupos, coisas ou lugares & 148 \\
\hline Relatos de situações cotidianas & 45 \\
\hline Vídeos & 39 \\
\hline Reflexões/opiniões sobre assuntos que me interessam & 97 \\
\hline Pensamentos sobre assuntos relacionadas à área da saúde ou contexto profissional & 71 \\
\hline Check-in em lugares & 48 \\
\hline
\end{tabular}

Tabela 2 - Tipo de conteúdo publicado.

Fonte: Elaboração própria com base na pesquisa de campo.

Quanto à produção de conteúdo próprio percebe-se que o uso mais frequente do Facebook é para inclusão de fotografias, considerando que quase todos os participantes já praticaram esse uso. Pouco mais de $50 \%$ das pessoas utiliza a rede social de forma espontânea para postar "reflexões/opiniões sobre assuntos que me interessam" e pouco mais de $40 \%$ para inclusão de "pensamentos sobre assuntos relacionadas à área da saúde ou contexto profissional". Se os usuários praticam isso habitualmente, ao se propor um uso pedagógico articulado com aprendizagens curriculares, terão facilidade e motivação para fazê-lo, estimulando a composição de uma comunidade de aprendizagem interativa. Em consonância com esse ganho pedagógico do Facebook "comunidades virtuais de aprendizagem (CVA) são definidas como redes virtuais de comunicação interativa organizadas em torno de interesses compartilhados" (MUSSOI; FLORES; BEHAR, 2015).

A aprendizagem em uma comunidade virtual no Facebook está alicerçada na interação e reciprocidade das produções. Cada participante (seja aluno ou professor) tem a possibilidade de contribuir com a comunidade, ao mesmo tempo que se beneficia com as publicações dos outros participantes. Criando-se assim um contexto de construção colegiado de saberes, uma vez que "o objetivo maior de uma CVA é a produção de 
inteligência coletiva, permitindo que todos os seus membros possam ser proficientes nos conteúdos compartilhados. Por isso, estimula-se a participação efetiva e o contato entre os sujeitos" (RIBEIRO; RAMOS, 2014, p.183).

\subsection{Interação em Grupos e Uso Pedagógico do Facebook}

A participação em grupos era a temática da sétima questão, cuja pergunta foi: "Se você participa de grupos no Facebook (para turmas e/ou disciplinas), marque as opções que representam a prática de utilização".

\begin{tabular}{|l|c|}
\hline \multicolumn{1}{|c|}{ Práticas de utilização em grupos criados para turmas ou disciplinas } & Ocorrên. \\
\hline Como um mural de avisos e recados relativos ao calendário acadêmico e compromissos & 130 \\
\hline Repositório de conteúdos (links, vídeos, etc.) como material complementar & 86 \\
\hline Realização de chats para organização de trabalhos e encaminhamentos entre alunos & 77 \\
\hline Realização de chats para tirar dúvidas com professores sobre conteúdo e rotina acadêmica & 22 \\
\hline Fórum: Assunto/questão de reflexão (com ou sem um link/ vídeo) - participação via comentário & 25 \\
\hline Criação de eventos para convite e organização de acontecimentos específicos & 52 \\
\hline Outros & 7 \\
\hline
\end{tabular}

Tabela 3 - Práticas de utilização em grupos ou disciplinas

Fonte: Elaboração própria com base na pesquisa de camp.

Com relação a participação de grupos criados para turmas ou disciplinas, observou-se que a maioria dos participantes, cerca de $33 \%$, fazem uso desta ferramenta como um mural, inserindo recados e avisos. É importante salientar que aproximadamente $25 \%$ dos usuários utilizam o chat para sanar dúvidas diretamente com o docente e para organização e encaminhamento de trabalhos com outros alunos. A opção "outros" possibilitava entrada de texto, algumas delas foram: "Aproximação de contato e troca de posts interessantes com alunos"; "Confirmação de presença no futebol"; "Divulgação de informações profissionais"; "mensagens de estímulo" e "Não utilizo para comunicação com os alunos".

A questão oito indagou sobre a utilização em situações acadêmicas pedindo que classificassem as alternativas (estabelecendo um ranking) demonstrando formas de uso vivenciadas ou que sabem que pessoas de seu relacionamento praticam. Os gráficos na figura 4 apresentam a totalidade de respostas obtidas.

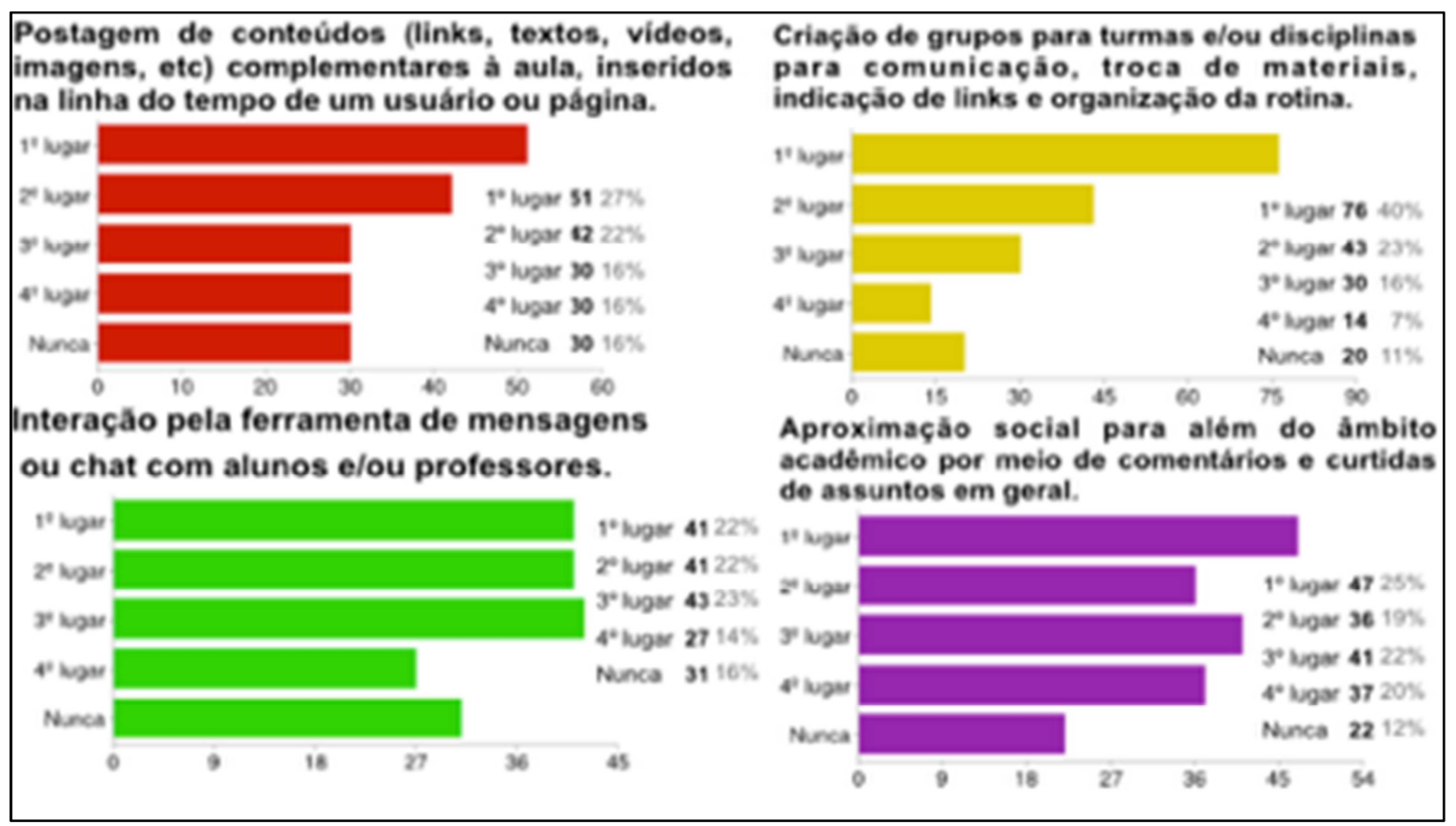

Figura 4 - Gráficos de respostas a respeito de formas de utilização no meio acadêmico Fonte: Elaboração própria com base na pesquisa de campo

A opção que mais se destacou foi relacionada a criação de grupos para turmas e/ou disciplinas voltadas a comunicação, troca de materiais, indicação de links e 
organização da rotina, totalizando $40 \%$ entre professores e alunos, seguida pela opção "postagem de conteúdos complementares à aula, inseridos na linha do tempo de um usuário ou página", com $27 \%$. As demais opções existentes para esta questão tratavam da "interação pela ferramenta de mensagens ou chat com alunos e/ou professores" e "aproximação social para além do âmbito acadêmico por meio de comentários e curtidas de assuntos em geral", totalizando $47 \%$ das respostas.

Os grupos do Facebook possibilitam criar "comunidades virtuais que permitem a troca de mensagens e conteúdos. (...) são usadas por grupos de estudantes e seus professores com o objetivo de produção de conhecimento a partir do compartilhamento de experiências de aprendizagem" (RIBEIRO; RAMOS, 2014, p.186). Nesse sentindo o Facebook permite o compartilhamento e construção conjunta de conhecimentos por meio da formação de grupos em que professores e alunos podem compartilhar saberes, interagir, tirar dúvidas e extrapolar os conteúdos de sala de aula de forma livre e criativa.

\subsection{Sugestões para utilização didática do Facebook e como ferramenta educacional}

As questões 9 e 10 eram discursivas e destinadas para sugestões didáticas para uso do Facebook na formação e as sugestões de utilização para profissionais da saúde como agentes educacionais. A questão 9, perguntava: "Considerando a visão de um aluno de graduação, cite 3 sugestões que você daria para um professor utilizar o Facebook como ferramenta didática para apoiar e complementar o trabalho de sala de aula". As respostas resultaram na prevalência do item "postagem de conteúdos complementares ao trabalho de sala de aula", selecionado por 27 professores e 91 alunos (79\% das respostas) como a sugestão mais importante de utilização para o ensino-aprendizagem. Esta opção foi seguida por "formação de grupos para turmas ou disciplinas", nas quais é possível usar fóruns, chats e formas de comunicação, para o esclarecimento de dúvidas, postagem de reportagens sobre temas de aulas, e a socialização de material de cunho científico. Essa segunda categoria obteve 20 ocorrências de os professores e 66 de alunos (47\% dos participantes). Poucos optaram pelo uso da ferramenta como instrumento motivacional (apenas 3\%).

No que diz respeito as sugestões de maneiras que os profissionais de saúde podem fazer uso do Facebook como agentes de educação em saúde (questão 10), 53 alunos e 16 docentes (38\% dos participantes) apontaram a divulgação de campanhas, eventos, palestras e encontros na área, como também a formação de grupos para reflexão coletiva sobre temáticas relevantes. Outras sugestões citadas foram a troca de experiências e informações entre profissionais e serviços de saúde, lembretes e dicas relacionados a saúde e qualidade de vida, perfazendo um total de 5 professores e 19 alunos (13\%). Tais resultados podem ser exemplificados pelos depoimentos a seguir: "Divulgação de políticas públicas" [...] "Postagens de informações sobre doenças e tratamentos" [...] "Evidenciando as práticas que são feitas" [...] "Postagens sobre doenças emergentes".

\subsection{Experiência pessoal de utilização e opção de não utilizar o Facebook}

Com relação a experiência com o Facebook, relatada em depoimentos na questão 11, os usuários destacaram vários pontos. Dentre os pontos positivos mais citados estão: contato ágil com as pessoas, divulgação de avisos, formação de grupos de trabalho, recebimento de informações atualizadas sobre a área da saúde, localização de pessoas, disseminação de notícias, divulgação de vagas de estágio/emprego e interação professor-alunos. E os pontos negativos: cyberbullying, invasão de privacidade, vitrine/vício, propagandas, pessoas que se expõe demais, agente distrator. Aqueles que expuseram pontos negativos não se manifestaram trazendo sugestões para resolvê-los. Vários relataram suas experiências pontuando as vantagens das redes sociais sem se posicionar quanto à mudanças.

A questão 12 era destinada para não usuários ou ex-usuários do Facebook (7\% dos participantes) para que se manifestassem com relação ao motivo de não aderirem a essa rede social. Dos 13 participantes que se manifestaram como não usuários a maioria 
destacou como motivos a manutenção da privacidade; experiências ruins que levaram a removerem o perfil e risco de vício por visibilidade e por saber sobre a vida de outrem.

\section{CONSIDERAÇÕES FINAIS}

Considerando os dados obtidos nesta pesquisa, pode-se concluir que a hipótese elaborada afirmando que o Facebook, na atualidade, é a rede social mais utilizada no Brasil, inclusive entre docentes e discentes de educação superior, foi confirmada. Percebe-se que a ferramenta contribui sobremaneira para a área da saúde, seja através das campanhas do Ministério da Saúde ou pela divulgação entre usuários, alertas sobre assuntos importantes, cursos nas mais diversas especialidades.

Reilly e Literat (2012) contribuem para a compreensão de que a participação em redes sociais que se estruturam como AVAs se dá por meio de quatro processos e complementares em uma "cultura participativa" (p. 18): afiliação, expressões, cultura participativa e solução colaborativa. A luz desses processos é possível perceber pela pesquisa realizada a contribuição do Facebook. O processo de afiliação diz respeito ao sentimento de pertencimento a uma comunidade, evidenciado pela adesão diária ao Facebook como uma rotina de vida por $86 \%$ dos participantes e em depoimentos que demonstram a importância da rede social para manter e aprofundar relacionamentos interpessoais.

As expressões são o segundo processo, que diz respeito as maneiras como os usuários se manifestam como autores ao publicarem conteúdos. Essas expressões foram observadas principalmente com relação ao envio de mensagens privadas para contato individual ou em grupos. Outro canal para a manifestação dessas expressões foi a participação em comunidades com contribuições ou comentários em postagens existentes (experiência de pouco mais de $50 \%$ dos participantes). Essas expressões, configurando publicações de autoria própria, relevantes para a construção de conhecimentos se materializam principalmente por meio de reflexões/opiniões sobre assuntos profissionais ou em destaque na sociedade, ou ainda pensamentos sobre assuntos relacionados à área da saúde ou contexto profissional (contemplando nesses dois itens cerca de $61 \%$ dos participantes). A postagem de imagens e fotografias é praticada por mais de $80 \%$, o que indica uma mídia fértil para o trabalho pedagógico com o Facebook.

O terceiro processo de cultura participativa é circulação, que gera sustentabilidade e visibilidade para as publicações criadas pelos usuários. A circulação ganha corpo nos grupos de Facebook que congregam pessoas reunidas por interesses comuns ou ainda grupos de turmas e disciplinas. Nesses grupos, as atividades pedagógicas mais evidentes são a composição de agenda e envio de recados $(71 \%)$; postagens que funcionam como repositório de conteúdos (links, artigos, vídeos, notícias, etc.) como material complementar (46\%); realização de chats para tirar dúvidas e organizar trabalhos $(54 \%)$. O quarto é a solução colaborativa de problemas, que estimula o trabalho em equipe para desenvolver algo novo. $\mathrm{O}$ trabalho em equipe e a reflexão conjunta de questões polêmicas e problemáticas da área de saúde apareceram em depoimentos na questão 10. Esses quatro processos integrados precisam ser estimulados e são pontos fortes quando se analisa o Facebook como ferramenta de aprendizagem colaborativa, evidenciando seus potenciais didático-pedagógicos.

Sendo considerada uma ferramenta midiática, e com objetivo de encontrar novas formas de interação social, para o ensino superior é possível explorar o Facebook de várias formas, como por exemplo, criando uma comunidade de aprendizagem para a turma/disciplina a fim de realizar discussões sobre assuntos vistos em aula, como apontado nos relatos. Nesta perspectiva, o ambiente concreto da sala de aula ganha novas dimensões ao sair do real para o ciberespaço. Assim, a exposição de um assunto, fruto de uma reflexão em sala de aula, pode estender-se para o ambiente das redes sociais ampliando as possibilidades de troca e construção de saberes. O que se busca não é apenas a incorporação de novas tecnologias com antigas formas de ensinar e aprender, mas de perceber o quanto a educação superior ganhe com novas práticas pedagógicas que agreguem redes sociais. 


\section{REFERÊNCIAS}

BELINE, W; MENTA, E; SALVI, R. F. EaD no mundo open source: construindo conhecimento com liberdade. Acesso em: 15/10/2007. Disponível em: $<$ http://www.escolabr.com/download/ artigos/artigo_ead.pdf $>$.

CASTELLS, Manuel. A sociedade em rede. São Paulo: Paz e Terra. v.1. 1999.

FOLHA DE S. PAULO. Uso do Facebook por crianças no Brasil é triplo da média mundial. Caderno de Tecnologia. Publicado em: 27/01/2014. Disponível em: http://www1.folha.uol.com.br/tec/ 2014/01/1401800-uso-do-facebook-por-criancas-no-brasil-e-triplo-da-media-mundial-diz-estudo.shtml

LEITE, Fernando B. T. No Brasil, o uso de telefones móveis se estende pelos níveis de renda e pelos grupos etários. Publicado em: 30/10/2013. Disponível em: http://www.hytrade.com.br.

LÉVY, Pierre. Cibercultura. Tradução de Carlos Irineu Costa. São Paulo: Ed. 34, 1999.

LITWIN, E. (org.) Educação a distância: temas para o debate de uma nova agenda educativa. São Paulo: Artmed, 2009.

MORAIS, Ricardo Prates. Redes sociais são essenciais como estratégia de marketing digital. Disponível em: http://www.artigonal.com/marketing-e-publicidade-artigos/redes-sociais-saoessenciais-como-estrategia-de-marketing-digital-7082177.html. Publicado em: 03/09/2014.

MUSSOI, E. M.; FLORES, M. L.P.; BEHAR, P. A. Comunidades virtuais: novo espaço de aprendizagem. Disponível em: www.cinted.ufrgs.br/ciclo9/artigos/8aEunice.pdf Acesso em: 06/02/2015.

FACEBOOK. Facebook Newsroom: Company Info. Disponível em: http://newsroom.fb.com/ company-info/. Acesso em 10/07/2015.

O ESTADO DE S. PAULO. Um terço dos brasileiros tem Facebook: País se torna o $2^{\circ} \mathrm{em}$ número de usuários. Caderno de economia e negócios. Publicado em 23/01/2013. Disponível em: http://blogs.estadao.com.br/radar-tecnologico/2013/01/23/um-terco-dos-brasileiros-tem-facebookpais-se-torna-o-2o-em-numero-de-usuarios/

OMENA, J. J. C.; ROSA, J. M. Estudos no Facebook: revisão sistemática dos métodos de investigação. Estudos em Comunicação, n18, p15-33. disponível em: <http://www.ec.ubi.pt/ ec/19/pdf/ec_19.pdf\#page=21>, acesso em 14/07/2015.

ONLINE COLLEGE (2011). 50 Reasons to Invite Facebook Into Your Classroom.

Disponível em http://www.onlinecollege.org/2011/07/18/50-reasons-to-invite-facebook-intoyourclassroom/. Acesso em: 17/11/2014.

PAGTEL; E.LIFE. Jovens brasileiros e o mundo móvel. Disponível em: www.pagtel.com.br. Publicado em: 04/10/2014.

POSSOLLI, Gabriela Eyng. Políticas de Educação Superior a distância e os pressupostos para formação de professores. Tese apresentada ao programa de pós-graduação em educação (PPGE) para obtenção do título de doutorado. Curitiba, UFPR, 2012. 235p.

REILLY, Erin; LITERAT, Ioana. Designing with teachers: participatory approaches to Professional Development in Education. USC Annenberg Innovation Lab. 2012.

RIBEIRO, M. E. M.; RAMOS, M. G. O ensino de Química por meio de comunidades virtuais de aprendizagem. Anais do 34 EDEQ: inovação no ensino de Química. Santa Cruz do Sul: UNISC, 2014.

RODEGHIERO, Carolina. Modelos de aprendizagem em mídias socias aplicados ao

Facebook durante as eleições de 2014. Anais do VIII Simpósio Nacional da ABCiber: Comunicação e Cultura na Era de Tecnologias Midiáticas. Disponível em: http://www.abciber. org.br/simposio2014/anais/GTs/carolina_campos_rodeghiero_79.pdf. Acesso em: 05/12/2014

SANTOS, A. V; VECHIA, A. Educação, computadores e internet: êxito no uso de ambientes virtuais de aprendizagem no ensino superior. In: IX Congresso da Sociedade Portuguesa de Ciências da Educação, Funchal: Universidade da Madeira, p. 1-10, 2007. 